\title{
Cleaning and disinfecting protocols for hospital environmental surfaces: A systematic review of the literature
}

\author{
Keyanna P. Taylor ${ }^{1}$, Debra D. Harris*2 \\ ${ }^{1}$ Public Health, Baylor University, Waco, TX, United States \\ ${ }^{2}$ College of Health and Human Sciences, Baylor University, Waco, TX, United States
}

Received: July 28, 2019

DOI: $10.5430 /$ jha.v8n6p27
Accepted: September 23, $2019 \quad$ Online Published: October 22, 2019

URL: https://doi.org/10.5430/jha.v8n6p27

\begin{abstract}
Background: Healthcare associated infections are a leading cause of illness and death in the United States and across the world. Environmental surfaces are considered non-critical, although recent evidence suggests that the built environment may contribute to the transmission of pathogens. Ineffective cleaning and disinfecting of environmental non-critical surfaces may increase risk of transmitting nosocomial pathogens leading to hospital acquired infections among hospital patients.

Objective: This systematic review identifies elements of cleaning and disinfecting protocols, synthesizing the evidence to evaluate cleaning protocols that effectively reduce surface contamination and minimize risk of hospital acquired illness.

Methods: A systematic literature review was conducted with a clearly formulated research question and systematic approach to identify publications, select relevant studies, critically appraise the research through analysis of reported data, and reported the results according to the Cochrane methodology.

Results: In total, 245 studies were initially identified with 19 studies meeting inclusion criteria. Emerging categories include chemical application methods, chemical application time, cleaning type and frequency, and interventions for training and monitoring.

Conclusions: Establishing adequate cleaning protocols for hospital environments is a complex process which requires consideration of multiple components including mechanical action, chemical application materials, types of cleaning, chemical contact times, education and training of EVS staff, cleaning monitoring and feedback, no-contact cleaning methods, and self-disinfecting surfaces. Recommendations for protocol development based on the study results are provided.
\end{abstract}

Key Words: Environmental services, Cleaning and disinfecting protocols, Non-critical, Hospital associated illness, Pathogen transmission, Environmental surfaces, Indoor environmental quality, Indoor environmental health

\section{INTRODUCTION}

Healthcare associated infections (HAI) are a leading cause of illness and death in the United States (USA) and worldwide. ${ }^{[1]}$ Annually, an estimated 1.7 million patients suffer with HAIs in the USA, leading to about 100,000 deaths. ${ }^{[2]}$ It is estimated that one of every twenty patients in U.S. acute care hospitals acquires an HAI, with the most prevalent pathogens being Clostridium difficile $(C$. diff) and

*Correspondence: Debra D. Harris; Email: debra_harris@baylor.edu; Address: Robbins College of Health and Human Sciences, One Bear Place \#97346, Waco, TX 76798-7346, United States. 
methicillin-resistant Staphylococcus aureus (MRSA). ${ }^{[2,3]}$

A pathogen is an infectious agent such as a bacterium, virus, fungus, parasite or other microorganism that causes disease in its host. The host may be a human, an animal, a plant, a fungus or other microorganisms. Building and finish materials may harbor pathogens, providing them with resources to sustain or grow, surviving on dry environmental surfaces for days to weeks and even months. ${ }^{[4]}$ Occupants in the healthcare environment are at risk of exposure to pathogens on environmental surfaces through three routes of transmission - inhalation, ingestion, and absorption.

Bioburden is the degree of microbial contamination (microbial load) or the number of microorganisms living on a surface. ${ }^{[4]}$ The surface may be an inanimate object (fomite) or an animate object (host). In the hospital environment, the bioburden is heaviest within three feet of the patient, indicating that beds, overbed tables, bedside tables, bed rails, and other surfaces near the patient area are expected to be heavily contaminated. Similarly, patient bathroom surfaces are areas where bioburden is high. These surfaces are categorized as non-critical environmental surfaces according to the Spaulding Classification System, a widely used system for coordinating the disinfection and sterilization of surfaces with known processes. ${ }^{[5]}$ In 1991 the CDC expanded the category of environmental non-critical surfaces to include two subgroups: housekeeping surfaces and medical equipment surfaces. These two subgroups use similar disinfectants and standards for cleaning.

While environmental non-critical surfaces only come in contact with intact skin, there is still potential for these surfaces to contribute to transmission of epidemiological important microbes, such as vancomycin-resistant Enterococci (VRE), MRSA, and other pathogens. ${ }^{[6]}$ Therefore, cleaning and disinfection of all patient areas, including non-critical environmental surfaces, is a crucial function for infection prevention. ${ }^{[7]}$

While cleaning protocols set by the Centers for Disease Control and Prevention (CDC) provide a basis for environmental cleaning and disinfection, there may be more recent information about how and when cleaning should occur. ${ }^{[8]}$ The guidelines provide information about cleaning environmental surfaces focused on the specific chemical disinfectants or detergents used. Additional factors stated as being influential such as the number of people in the environment, amount of activity, amount of moisture, type of surface, and orientation are discussed. ${ }^{[8]}$ However, there are other considerations that may play a role in ensuring cleaning efficacy such as cleaning materials, time, and frequency. Cleaning should be tailored specifically to the clinical risk given the varying types of surfaces and equipment. ${ }^{[9]}$ Many hospitals have unique cleaning specifications per area while other hospitals are working to develop and proposed national standards. It has been suggested that there are still too many gaps in the knowledge to establish cleaning as an evidencebased science that can be translated to specifics in healthcare environments. ${ }^{[9]}$ Contributing to the evidence-base is fundamental in preventing the spread of HAIs because insufficient disinfecting, ineffective disinfecting materials, and failure to disinfect for required time and frequency may encourage the re-emergence of HAI cases.

Specific guidelines provided by the CDC for cleaning and disinfecting environmental surfaces are: 1) clean environmental surfaces (e.g., floors, tabletops) on a regular basis, when spills occur, and when surfaces are visibly soiled; 2) disinfect (or clean) environmental surfaces on a regular basis (e.g., daily, three times per week) and when surfaces are visibly soiled; and 3) follow manufacturers' instructions for proper use of disinfectant (or detergent) products-such as recommended use (dilution), material compatibility, storage, shelf life, and safe use and disposal). ${ }^{[6]}$ These guidelines are at times vague and open the opportunity for hospitals to interpret the recommendations in a variety of ways. ${ }^{[8]}$

Daily cleaning with high-performance disinfectants may still be ineffective if correct procedures are not employed. ${ }^{[10]}$ With recommendations to perform cleaning without a welldefined schedule, hospitals may employ daily routine cleaning, various types of terminal cleaning, or enhanced cleaning using their own interpretation of "regular basis". Furthermore, while recommendations exist for the selection and use of detergents and disinfectants, there is a dearth of corresponding recommendations for cleaning equipment and materials. ${ }^{[10]}$ For example, one type of cleaning material often used are disinfectant wipes. However, wipes utilized to disinfect surfaces in close proximity to patients (e.g., bed rails, call buttons) and those commonly touched by staff and patients (e.g., overbed tables, keyboards) may act as sources of cross contamination. ${ }^{[11]}$ Simply put, the current guidelines for cleaning environmental surfaces lack specificity for how chemicals are applied, when cleaning and disinfection occurs, and other factors to consider for the practical development of protocols for cleaning and disinfecting environmental surfaces. The aim of this systematic review was to evaluate the components of cleaning protocols for environmental surfaces in hospital settings since the publication of the CDC guidelines. ${ }^{[6,8]}$ While there are specific guidelines and recommendations published including and since the CDC guidelines, there are no comprehensive guidelines available to inform the cleaning and disinfecting of environmental surfaces. 


\section{MeTHOdS}

The methodology of this systematic literature review followed the Cochrane Handbook for Systematic Reviews of Interventions, an established guide to conducting reviews of healthcare interventions. ${ }^{[12]}$

\subsection{Search/keywords}

The literature search was conducted using One Search, Academic Search Complete, LISTA (EBSCO), PubMed, and Web of Science using MeSH terms.

As shown in Table 1, search term list was developed from several sources and refined during the initial search.

\subsection{Inclusion criteria}

Initial criteria included experimental and quasi-experimental research designs with quantitative data, published since 1980, available in the English language, and available through online research databases. Records were excluded if not relevant (e.g. commentaries, reviews, studies with no statistics reported), possessed confounding variables, were not specific to human healthcare environments, or had critical limitations (e.g. sample size, missing data, lack of available or reliable data). A search was conducted, followed by an initial review based on the title and abstract of each record.

\subsection{Data extraction}

Full-text articles were downloaded for the remaining records and reviewed, focusing on inclusion and exclusion criteria. Two reviewers performed the data extraction. A random selection of studies was checked by the second reviewer for accuracy. Studies were coded by type and category and approved by consensus. Studies meeting inclusion criteria were evaluated using a peer-reviewed article rating system. ${ }^{[13]}$ The final review for inclusion was a blind review on the remaining studies for data analysis, specifically whether the study included statistic(s), the appropriate selection of statistics used, the sample size, and the effect size; all factors contributing to statistical power.

\subsection{Analysis}

The quality appraisal process was conducted using a peer reviewed article rating tool. ${ }^{[13]}$ The article rating tool used in this study was validated using Cohen's Kappa Weighted to measure the agreement between two raters for inter-rater reliability. ${ }^{[13,14]}$ The rating system process used search parameters, including identifying databases for inclusion, search terms, and sources of evidence. Specific inclusion criteria were developed prior to full-text assessment to determine eligibility. A critical analysis of the published research using a structured method was performed. ${ }^{[15-18]}$
The article rating system is based on two prerequisites and a 100-point score assigned across six major study design levels. The maximum possible points allocated to each study design level are weighted based on the literature, which provides an orderly approach for qualifying evidence. ${ }^{[16,18-20]}$ After the article was evaluated, a predetermined designated baseline score of 70 established inclusion for the systematic literature review. Using the article rating system tool, data was extracted to evaluate study characteristics, participant characteristics, intervention, setting, and results. The reference management software, EndNote X9, was used to manage searches and write the final review.

\section{RESUlts}

The initial search found 245 database records using the search terms and phrases (see Table 1). Twenty-nine duplicates were removed lowering the number of records screened to 216 . An initial review was performed in which 151 records were excluded, reducing the number of records to 65 . A review of full-text articles based on inclusion and exclusion criteria netted thirty-four articles found to be relevant to cleaning protocols. Quality appraisal was assessed for the 34 articles using the article rating tool. Of those, 15 did not meet inclusion criteria, leaving 19 remaining in the study. The results of the literature search are shown in Figure 1. The 19 remaining studies all examined different aspects of cleaning protocols. Among those, four subgroups emerged: 1) chemical application methods; 2) chemical application time; 3 ) cleaning type; and 4) interventions.

\subsection{Chemical application methods}

The subgroup, chemical application methods, included 5 studies that explored how cleaning agents are applied using a variety of materials or systems to clean a surface.

The studies focused on chemical application methods are shown in Table 2 with detailed explanations following. In a study conducted in a university tertiary hospital, 3 cleaning methods for floors (mop and vacuum, spray clean, and wet scrub) and 1 cleaning method for curtains (steam) were evaluated. ${ }^{[21]}$ Results showed that all floor cleaning methods reduced the overall microbial load, though high microbial counts and bacterial pathogens sometimes persisted. Wet scrubbing was the most productive, significantly reducing levels of coagulase-positive staphylococci, which, in combination with routine methods, produced an effect that remained for at least a week. Steam cleaning the curtains also reduced microbial counts but had little effect on potential pathogens. 
Table 1. Search terms for the systematic literature review evaluating protocols for environmental surface cleaning and disinfection

\begin{tabular}{llll}
\hline Search Terms & & & \\
\hline Chemical & Education & Housekeepers & Protocol \\
Cleaning & Environmental & Housekeeping & Surface \\
Cleaning Efficacy & Environmental Services & Non-Critical & Transmission \\
Disinfectants & EVS & Pathogen & Ultraviolet-C (UVC) \\
Disinfecting & Healthcare & Patient Room & \\
Disinfection & Hospital & Plasma & \\
\hline
\end{tabular}
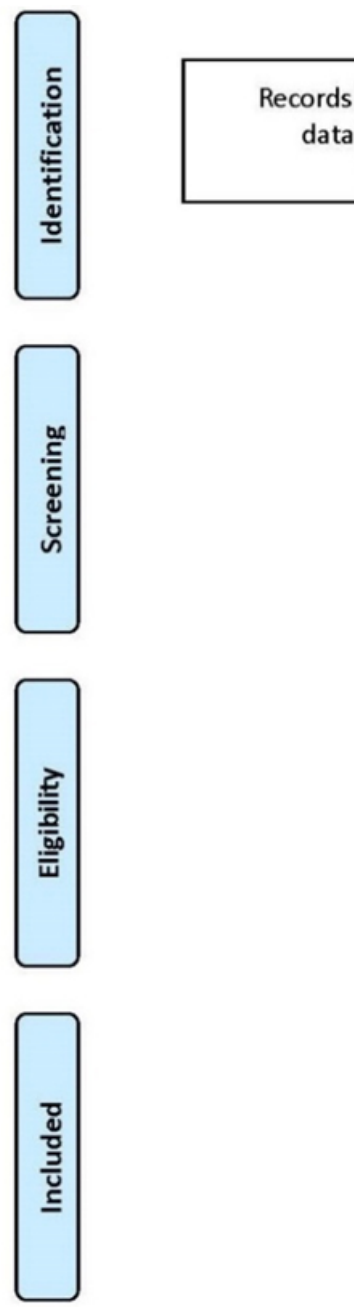

database searching
datentified through ( $n=245)$

Additional records identified through other sources

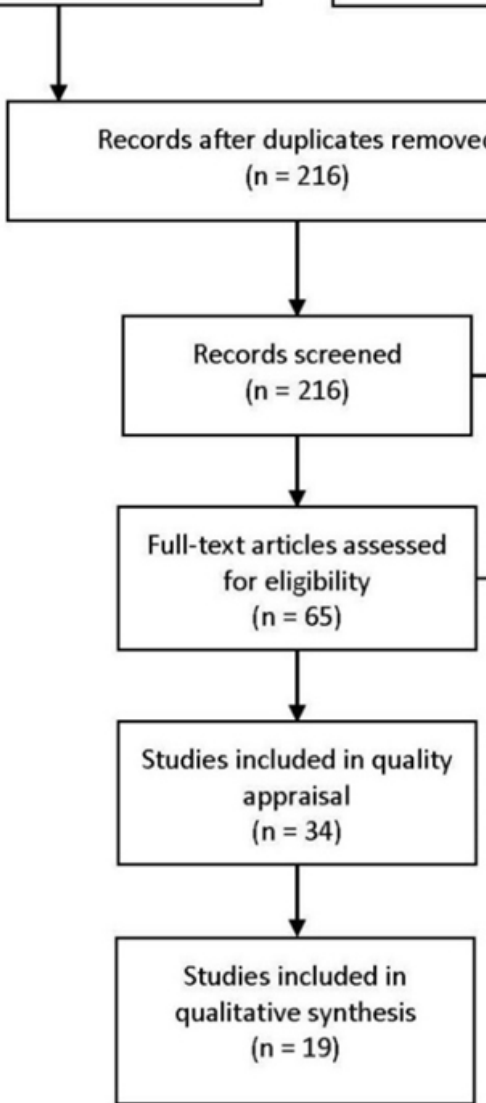

Figure 1. Literature search protocol following Preferred Reporting Items for Systematic Reviews and Meta-Analyses (PRISMA) criteria. ${ }^{[22]}$

A study comparing two wipe methods was conducted using a pre-intervention and intervention strategy. ${ }^{[23]}$ The preintervention used reusable wipes soaked in sodium hypochlorite; and the intervention utilized disposable wipes of 4 different colors to clean various areas. In the pre-intervention the wipes were washed with detergent and water after use, dried and stored for reuse daily. The wipes were only replaced if damaged. Cleanliness was evaluated with visual assessment. During the intervention, the wipe groups were as follows: red wipes for high contamination risk areas (discarded daily), yellow wipes for bed-side areas (discarded post-terminal cleaning), green wipes for nursing station/meeting areas (dis- 
carded every 3 days), and blue wipes for public areas (discarded every 3 days). Sites during the intervention were evaluated for cleanliness using ATP bioluminescence. The total number of clean high-touch sites increased from $13 \%$ to $53 \%$ and the total of unclean high-touch sites decreased from
$47 \%$ to $20 \%$. Evaluation method was a limitation of the study since the pre-intervention used a visual assessment while the intervention used ATP bioluminescence (ATP); however, the use of disposable wipes of different colors designated for specific areas may improve environmental cleanliness.

Table 2. Characteristics of studies investigating chemical application methods

\begin{tabular}{|c|c|c|c|c|}
\hline Authors (date) & Microbe & Location & Process & Outcome \\
\hline Hopman et al. (2015) & $\begin{array}{l}\text { Microbial } \\
\text { contamination }\end{array}$ & Hospital beds & $\begin{array}{l}\text { Manual versus mechanical cleaning } \\
\text { procedures. }\end{array}$ & $\begin{array}{l}\text { Reduction in contamination } \\
\text { was greater after mechanical } \\
\text { cleaning. }\end{array}$ \\
\hline Li et al. (2017) & MRSA & NICU HTOs & $\begin{array}{l}\text { Cleaning with cotton cloths versus cleaning } \\
\text { with color coded microfiber cloths. } \\
\text { Introducing use of bleach disinfectant } \\
\text { wipes. } \\
\text { Introducing mechanical methods of } \\
\text { cleaning and drying used wipes. } \\
\text { Training of EVS. }\end{array}$ & $\begin{array}{l}\text { Total MRSA contamination } \\
\text { decreased after instituting new } \\
\text { protocols. }\end{array}$ \\
\hline Mehmi et al. (2009) & $\begin{array}{l}\text { B. subtilis, } \\
\text { B. pumilis }\end{array}$ & $\begin{array}{l}\text { Hospital } \\
\text { pharmacy } \\
\text { cleanrooms }\end{array}$ & $\begin{array}{l}\text { Various biocides applied by spraying, } \\
\text { wiping, and spraying plus wiping. }\end{array}$ & $\begin{array}{l}\text { Spraying followed by wiping } \\
\text { was most effective, followed } \\
\text { by wiping with a } \\
\text { disinfectant-impregnated wipe }\end{array}$ \\
\hline White et al. (2007) & $\begin{array}{l}\text { Bacterial } \\
\text { pathogens }\end{array}$ & Floors, curtains & $\begin{array}{l}\text { Mop and vacuum, spray clean and wet } \\
\text { scrub methods evaluated for floors, and one } \\
\text { steam cleaning method evaluated for } \\
\text { curtains. }\end{array}$ & $\begin{array}{l}\text { All methods removed } \\
\text { microbial load with wet } \\
\text { scrubbing most effective. }\end{array}$ \\
\hline Wong et al. (2018) & None & HTOs & $\begin{array}{l}\text { Reusable wipes versus disposable wipes of } \\
\text { four different colors. }\end{array}$ & $\begin{array}{l}\text { Disposable color-coded wipes } \\
\text { improved cleanliness. }\end{array}$ \\
\hline
\end{tabular}

A three-phase study ${ }^{[24]}$ evaluated the quality of mechanical versus manual bed cleaning regimens. Manual cleaning involved wiping with a cloth impregnated with a quaternary cleaning solution. Mechanical cleaning involved a bed washer/disinfector system using a quaternary cleaning solution. The environmental services (EVS) team was trained and evaluated. Then the cleaning quality of the manual and mechanical regimens were assessed using microbiological analysis on 40 samples and ATP analysis on 20 samples. During the final phase, manual cleaning was introduced over a 2-month period from one unit, while beds from other departments were mechanically cleaned. The results showed that training improved the quality of cleaning and, with a benchmark for clean set at 100 or less RLUs for ATP readings, mechanical cleaning resulting in significantly lower ATP levels than manual cleaning.

In a 5-year study that evaluated the impact of relocation on environmental cleaning and the reduction of hospital acquired infections (HAI) in a NICU, ${ }^{[25]}$ new environmental cleaning protocols were adopted for the new NICU. The study focused on comparing MRSA counts on high-touch objects (HTOs) and incidence density of HAIs between the baseline and intervention periods. During the baseline period, routine cleaning comprised of cotton cloths and a bucket with detergent used for all surfaces, followed by routine disinfection with a bleach solution. The intervention period implemented the use of color cloths, coded for individual use per patient zone, followed by the same routine disinfection with a bleach solution. During the intervention period, only $2.5 \%$ of environmental surfaces were positive for MRSA compared to $44 \%$ during the baseline period. Similarly, the total incident rate of HAIs significantly declined from 16.8/1,000 days during the baseline period to $10 / 1,000$ days during the intervention period.

Mehmi, Marshall ${ }^{[26]}$ investigated other agents and application methods that may have greater efficacy against spores of Bacillus subtilis (B. subtilis) and Bacillus pumilis (B. pumilis) than industrial methylated spirit spray for surface disinfection of pharmaceutical environments. In this study, stainless steel carrier test plates were used to represent hard surfaces in hospital pharmacy cleanrooms. Plates were inoculated with $10^{7}-10^{8} \mathrm{CFU} / \mathrm{mL}$ and treated with various biocide formulations using different disinfection methods. The biocides were applied by spraying, wiping, and spraying plus wiping. The 
carriers were exposed to a two-minute spray contact time and a two-minute wiping time with each of the tested biocides. Sporicidal activity was calculated as log reduction in CFU. When comparing application methods, spraying followed by wiping was significantly more effective, followed by wiping with a disinfectant-impregnated wipe. Spraying alone was least effective.

\subsection{Length of time for chemical application}

The subgroup, length of chemical application, included 2 studies. These studies focused on how long chemical disinfectant/detergents remain in contact with a surface to achieve appropriate disinfection.

The evidence for length of chemical application is limited as indicated by Table 3. In a study conducted by Boyce,
Havill $^{[27]}$ the time for cleaning surfaces with wipes soaked in quaternary ammonium disinfectant was examined. Seven housekeepers participated in an observational study that included ATP readings and reporting of median cleaning times while performing daily cleaning of 5 high touch objects (HTO). Median cleaning times for HTOs were: bedrails (86 seconds), overbed tables (66 seconds), television remote controls (12 seconds), bathroom grab bars (22 seconds), and toilet seats ( 75 seconds). A study consisting of a systematic review and observation ${ }^{[28]}$ examined the amount of time to clean specific items and found no significant differences between non-clinical, nursing, and EVS staff in the median time to clean HTOs, including: bed rails (66 seconds), bedside table (83 seconds), call system (31 seconds), blood pressure cuff (29 seconds), and IV drip (51 seconds).

Table 3. Characteristics of studies investigating length of chemical application

\begin{tabular}{|c|c|c|c|c|}
\hline Authors (date) & Microbe & Location & Process & Outcome \\
\hline Boyce et al. (2010) & None & HTOs & $\begin{array}{l}\text { Housekeeper cleaning times and number } \\
\text { of disinfectant wipes used evaluated }\end{array}$ & $\begin{array}{l}\text { Variations among cleaning staff in } \\
\text { cleaning time and number of wipes }\end{array}$ \\
\hline Scott et al. (2017) & None & HTOs & EVS time required to clean HTOs & $\begin{array}{l}\text { No variation among EVS staff in cleaning } \\
\text { times }\end{array}$ \\
\hline
\end{tabular}

Table 4. Characteristics of studies investigating cleaning type and frequency

\begin{tabular}{lllll}
\hline Authors (date) & Microbe & Location & Process & Outcome \\
\hline Amin et al. (2014) & Organic Material & HTOs & $\begin{array}{l}\text { Types of terminal cleaning } \\
\text { evaluated }\end{array}$ & $\begin{array}{l}\text { Enhanced terminal cleaning most effective } \\
\text { in reducing organic material }\end{array}$ \\
Chen et al. (2017) & Surface microbiota & HTOs & $\begin{array}{l}\text { Daily plus terminal cleaning } \\
\text { versus terminal cleaning alone }\end{array}$ & $\begin{array}{l}\text { Higher abundance of microbial diversity } \\
\text { with terminal cleaning only }\end{array}$ \\
\hline
\end{tabular}

\subsection{Cleaning type and frequency}

The subgroup, cleaning type and frequency, included 2 studies that evaluated what kind and when cleaning and disinfection was employed.

These studies compared the impacts of daily or routine cleaning and terminal or discharge cleaning as shown in Table 4. A study by Amin, Folkert ${ }^{[29]}$ compared the effectiveness of 3 room cleaning procedures (baseline terminal, directed terminal, and enhanced terminal) and used ATP to audit cleaning of 9 HTOs, near patient surfaces in medical office-based intravitreal injection rooms. The 9 HTOs were the examination chair arm rest, back, and seat; the keyboard and mouse, desktop, telephone, sink and faucet handle, medication cabinet handles, and door handles inside and out. In baseline terminal cleaning, injection rooms were cleaned at the end of each day by technicians with Oxivir TB disinfectant wipes presoaked with hydrogen peroxide. Cleaning was concluded based upon visual perception of cleanliness and another round of institutional terminal cleaning was performed by janitorial services with disposable wipes soaked in a quaternary cleaning solution. Directed terminal cleaning was the same as baseline, but staff were told to pay particular attention to the 9 HTOs and told that the 9 surfaces would be randomly monitored for cleanliness. ${ }^{[29]}$ Terminal cleaning was concluded upon visual perception. Lastly, enhanced terminal cleaning was the same as directed terminal cleaning except the 9 HTOs were cleaned between patients throughout the day. Prior to baseline terminal and directed terminal cleaning, the RLU values were 780 and 626, respectively. Following baseline and directed terminal cleaning, the median RLU was 391 and 264, respectively. During enhanced terminal cleaning, the median RLU value was significantly lower (71 RLU). In summary, this study concluded that an enhanced terminal cleaning program decreased surface bioburden in intravitreal injection rooms. 
Chen, $\mathrm{Tu}^{[30]}$ investigated the impact of two cleaning methods (daily plus terminal cleaning and terminal cleaning alone) on bacterial community diversity in two hospital wards. The study compared the persistence of A. baumanni colonization among the two cleaning methods. The terminal disinfection procedure comprised of EVS staff wiping the surface (bed, monitor, ventilator, and stethoscope) with 500-ppm hypochlorite, keeping it wet for 30 minutes and then wiping it again with a clean cloth and clean water; and EVS staff changing the curtain, mattress, and quilt. Daily cleaning included wip- ing the bed bar monitor, ventilator, stethoscope, oxygen supply and suction button, hemodialysis machine, intravenous pump and feeding pump with the 500-ppm hypochlorite only without waiting $30 \mathrm{~min}$ to wipe with a clean cloth and water. Results of the study found that a significantly higher abundance of microbial diversity was found in the ward that utilized terminal cleaning only. It was concluded that altering the type and timing of cleaning (daily and/or terminal) may contribute to differences in microbial communities among hospital surfaces.

Table 5. Characteristics of studies investigating training and education

\begin{tabular}{|c|c|c|c|c|}
\hline Authors (date) & Microbe & Location & Process & Outcome \\
\hline Carling et al. (2006) & None & HTOs & $\begin{array}{l}\text { Terminal cleaning evaluated with } \\
\text { Fluorescent targeting solution removal }\end{array}$ & $\begin{array}{l}\text { Targeting method effective in } \\
\text { assessing cleaning practices }\end{array}$ \\
\hline Carling et al. (2006) & None & HTOs & $\begin{array}{l}\text { Terminal cleaning evaluated with } \\
\text { Fluorescent targeting solution removal }\end{array}$ & $\begin{array}{l}\text { Targeting method effective in } \\
\text { assessing cleaning practices }\end{array}$ \\
\hline Carling et al. (2008) & None & HTOs & $\begin{array}{l}\text { Terminal cleaning evaluated with } \\
\text { Fluorescent targeting solution removal }\end{array}$ & $\begin{array}{l}\text { Targeting method effective in } \\
\text { assessing cleaning practices }\end{array}$ \\
\hline Carling et al. (2008) & None & HTOs & $\begin{array}{l}\text { Terminal cleaning evaluated with } \\
\text { Fluorescent targeting solution removal }\end{array}$ & $\begin{array}{l}\text { Targeting method effective in } \\
\text { assessing cleaning practices }\end{array}$ \\
\hline Carling et al. (2010) & None & HTOs & $\begin{array}{l}\text { Terminal cleaning evaluated with } \\
\text { Fluorescent targeting solution removal }\end{array}$ & $\begin{array}{l}\text { Targeting method effective in } \\
\text { assessing cleaning practices }\end{array}$ \\
\hline Eckstein et al. (2007) & CDAD, VRE & HTOs & $\begin{array}{l}\text { Terminal cleaning evaluated after an } \\
\text { educational intervention }\end{array}$ & $\begin{array}{l}\text { Environmental contamination after } \\
\text { EVS cleaning significantly reduced }\end{array}$ \\
\hline $\begin{array}{l}\text { Goodman et al. } \\
(2008)\end{array}$ & MRSA, VRE & HTOs & $\begin{array}{l}\text { Fluorescent marker removal after } \\
\text { discharge cleaning }\end{array}$ & $\begin{array}{l}\text { Reduced the likelihood of a } \\
\text { positive environmental culture for } \\
\text { MRSA or VRE }\end{array}$ \\
\hline $\begin{array}{l}\text { Munoz-Price et al. } \\
\text { (2012) }\end{array}$ & $\begin{array}{l}\text { Environmental } \\
\text { cultures }\end{array}$ & $\begin{array}{l}\text { Operating } \\
\text { rooms } \\
\text { surfaces }\end{array}$ & $\begin{array}{l}\text { Cleaning practices and removal of a } \\
\text { fluorescent gel marking system (DAZO) } \\
\text { after cleaning }\end{array}$ & $\begin{array}{l}\text { Environmental cultures and UV } \\
\text { marker removal both increased }\end{array}$ \\
\hline Ragan et al. (2012) & None & HTOs & Fluorescent marker removal & Increased number of cleaned HTOs \\
\hline Sitzlar et al. (2013) & C. difficile & HTOs & $\begin{array}{l}\text { Three-phase fluorescent marker } \\
\text { intervention }\end{array}$ & $\begin{array}{l}\text { Reduced prevalence of positive } \\
\text { cultures of } C \text {. diff }\end{array}$ \\
\hline
\end{tabular}

\subsection{Training and education}

The subgroup, training and education, included 10 studies as shown in Table 5, examining the impact of implementing training or feedback interventions to educate EVS staff on cleanliness.

The first 5 studies were similar in methodology and used a chemical marker that fluoresced when exposed to ultraviolet light. The process required physically marking the objects then using UV light to determine whether the object has been cleaned or not. It was subjective and required a visual assessment with most studies using a pass/fail approach. The chemical marker was used as a feedback system to evaluate the thoroughness of cleaning HTOs in the patient environment. ${ }^{[31-35]}$ The chemical marker was used to provide feedback for educational programs for EVS staff with the intention to improve cleaning thoroughness.
One study included three hospitals where the average rate of objects cleaned was about $48 \%$. After the baseline period, a structured, multidisciplinary educational intervention was developed for the EVS staff of each hospital. After the intervention, the average cleaning of objects improved to $83.3 \%$. High rates of cleaning, between $80 \%$ and $92 \%$, were found for toilet tops, bedside tables, overbed tables, and sinks. Low rates of cleaning, between $12.3 \%$ and $18 \%$ of rooms overall, were found for bedpan cleaning equipment, patient room and bathroom doorknobs/pulls, and toilet grab bars. ${ }^{[32,33]}$

Another study assessed the ability of a structured intervention program to improve the quality of cleaning and reduce environmental transmission of multidrug-resistant organisms (MDROs) within the intensive care unit. ${ }^{[34]}$ At baseline, only $49.5 \%$ of surfaces were cleaned. After the intervention and multiple cycles of objective performance feedback to 
EVS staff, the thoroughness of cleaning improved to $82 \%$ of environmental surfaces.

Carling, Von Beheren ${ }^{[35]}$ evaluated the thoroughness of disinfection and cleaning in the patients' immediate environment and identified opportunities for improvement in a dissimilar group of acute care hospitals. There were variations within object categories that were notable with the overall thoroughness of terminal cleaning being $49 \%$. Mean cleaning rates were less than $30 \%$ for toilet grab bars, bedpan cleaners, light switches, and doorknobs. Other HTOs that were inconsistently cleaned included patient telephones, nurse call devices, and bedside rails. Sinks, toilet seat, and overbed tables were consistently more successful with a mean cleaning rate over 75\%. Opportunities for improvement of cleaning HTOs were found in all the participating hospitals. The information gleamed from these assessments may be used to develop focused interventions (educational and operational) that incorporate ongoing feedback to EVS staff to improve cleaning and disinfection practices in healthcare environments.

A prospective before and after study with 3 phases ${ }^{[31]}$ tested HTOs to evaluate and improve current cleaning practices. Phase I was the pre-intervention analysis; Phase II was the programmatic analysis and educational interventions; and Phase III initiated performance feedback and programmatic analysis. Only $48 \%$ of HTOs were cleaned at baseline during Phase 1. After Phase II interventions were implemented and terminal cleaning improved significantly $(61 \%)$. During Phase III, additional performance feedback was provided to EVS staff. As a result, the overall thoroughness of cleaning improved significantly (77\%), however results varied widely between hospitals for all phases.

Cleaning practices of operating room technicians and EVS staff were evaluated in a study by Munoz-Price, Birnbach ${ }^{[36]}$ Operating room technicians cleaned during the day after individual patients. The EVS staff cleaned at the end of the workday after the last procedure. The study used a marking system with UV light assessment to conduct an intervention reporting the results as a feedback/educational component for the staff. The surfaces included bed control panels, anesthesia-related equipment (keyboards, knobs, switches, oxygen reservoir bags, and adjacent medication drawers), Mayo stands, over-table lamps, and floors (within 3 feet of the operating room table). In total, 194 operating rooms and 2,820 high risk objects were evaluated. The percent of cleaned objects increased from $47 \%$ at baseline to $82 \%$ during the last month of observations. However, the number of samples from which pathogenic organisms (MRSA, and Enterococcus species) were recovered did not change throughout the study. Pathogens were identified on $16.6 \%$ of surfaces at baseline and $12.5 \%$ of surfaces during the intervention period. In contrast, the number of surfaces from which gram-negative bacilli were recovered decreased from $10.7 \%$ at baseline to $2.3 \%$ during the intervention period.

Additional studies shared the objective to implement an audit and feedback protocol to increase cleaning thoroughness of HTOs. Ragan, Khan ${ }^{[37]}$ found that the number of HTOs cleaned significantly increased from $38 \%$ at baseline to $68 \%$ during the intervention on a medical unit. The thoroughness of individual objects varied widely during the baseline period, from $0 \%$ for a toilet grab bar to $93 \%$ for an overbed table. After the intervention, all surfaces were cleaned at $40 \%$ or higher. Within the same study, similar results were found in a cardiac care unit, where the number of HTOs cleaned increased from $53 \%$ at baseline to $78 \%$ during the intervention with the $80 \%$ target achieved within 3 weeks. Thoroughness of cleaning individual objects ranged from $13 \%$ (light switch) to $89 \%$ (countertop).

A prospective before and after intervention study was performed to assess efficacy of terminal cleaning and disinfection practices in rooms of patients with $C$. diff and VRE infection or colonization. ${ }^{[38]}$ Data collection included sampling from patients and HTOs in the patient environment after EVS staff cleaned, then again after research staff performed a disinfection process using a $10 \%$ bleach solution. EVS staff were provided feedback and education. Ninety-four percent of rooms with VRE infected or colonized patients had one or more positive environmental cultures before cleaning. After EVS cleaned, the environmental cultures were reduced to $71 \%$ of rooms. After disinfection with bleach, the number of environmental samples with positive cultures for VRE was reduced to zero. One-hundred percent of the rooms with patients positive for $C$. diff had positive cultures prior to cleaning. After cleaning, $78 \%$ of rooms had positive cultures after EVS cleaning with further reductions to $11 \%$ of rooms after bleach disinfection by research staff. After an educational intervention, rates of environmental contamination after EVS cleaning were significantly reduced.

Goodman, Platt ${ }^{[39]}$ utilized a chemical fluorescent marker visible under a UV lamp to assess whether an intervention involving improved cleaning practices, staff education, and rapid feedback using the UV monitoring system would impact the thoroughness of terminal cleaning and the environmental prevalence of MRSA and VRE in intensive care rooms. The cleaning practices that this study explored were two different chemical application methods. The intervention period altered the application method from pour bottles of solution on cotton cloths to the immersion of cloths in buckets of solution. During the baseline period, 545 surfaces were 
marked and assessed for cleaning thoroughness. During the intervention period, 576 surfaces were marked and assessed for cleaning thoroughness. Increasing the volume of disinfectant through immersion, providing education for EVS, and using a UV fluorescent marker system to provide feedback improved cleaning and disinfecting of environmental surfaces and reduced frequency of contamination of MRSA and VRE. This study found that broad, flat surfaces were more likely to be cleaned than were doorknobs, sinks, or toilet handles.

Sitzlar, Deshpande ${ }^{[40]}$ implemented three interventions: 1) fluorescent markers for monitoring; 2) an automated UV radiation device for $C$. diff patient rooms; and 3) enhanced standard disinfection of $C$. diff patient rooms. The fluorescent marker intervention improved thoroughness of cleaning HTOs from $47 \%$ to $81 \%$ marker removal. Relative to the baseline, the prevalence of positive cultures of $C$. diff infection rooms were reduced by $14 \%, 48 \%$ and $89 \%$ with interventions 1,2 , and 3 , respectively. The percentage of C. diff rooms with positive cultures after disinfection were reduced to $57 \%, 35 \%$, and $7 \%$, respectively.

\section{Discussion}

Protocols for cleaning environmental surfaces in the hospital setting may involve surface contact with a detergent or disinfectant alone or may incorporate mechanical action in the form of wiping or mechanical washing systems. Cleaning and disinfecting of hospital beds for example, is more effective when a mechanical bed washer is utilized. ${ }^{[24]}$ Wiping surfaces with detergents or disinfectants is also more effective than chemical contact time alone. ${ }^{[22,26,41]}$ Certain pathogens, such as $C$. diff spores, may adhere to surfaces, requiring abrasive wiping action to remove them. ${ }^{[41]}$

Uncertainty remains about what materials should be used to clean and disinfect surfaces. Disposable pre-soaked wipes or cotton, microfiber and other cloth reusable wipes are materials often used to complete mechanical wiping action. Several studies reported that disposable pre-soaked wipes were more effective than reusable wipes. ${ }^{[23,25]}$ However, other studies suggested that disposable wipes, if not used correctly, may contribute to cross contamination of other environmental surfaces while cleaning. ${ }^{[42,43]}$ Disposable wipes may contribute to transfer of bacteria and spores to other surfaces if they are used incorrectly. ${ }^{[44]} \mathrm{Li}, \mathrm{Xu}^{[25]}$ and Wong, Huang ${ }^{[23]}$ used a wipe color coding system to categorize which disposable wipes were used on specific surfaces resulting in improved cleanliness. By categorizing wipes into specific areas of the patient environment, cross contamination may be minimized. One limitation of disposable wipes is the potential risk of microbial contamination during storage in wipe dispensers.

Published by Sciedu Press
Therefore, the protocol must include a verification process if using disposable wipes. ${ }^{[45]}$ Disposable antibacterial wipes were also found to be as effective as microfiber reusable wipes when used immediately after contamination ${ }^{[46]}$ with microfiber cloths only demonstrating superior efficacy at removing absorbed soil after 24 hours. ${ }^{[46]}$

When examining reusable materials, several studies found that microfiber cloths and microfiber mops were more effective at microbial removal when compared to cotton cloths or cotton mops. ${ }^{[47,48]}$ However, microfiber cloths were not as effective as cotton cloths after multiple uses. ${ }^{[10]}$

Contrasting information exists when comparing microfiber cloths. ${ }^{[49]}$ Several studies indicated that when using reusable wipes, processing of the wipes after use has shown to decrease efficacy over time and increase cross contamination to other surfaces during use. ${ }^{[49-51]}$ However, other research found that microfiber cloths increased in efficacy after multiple cycles of reprocessing. ${ }^{[52]}$

Differing results from studies focused on microfiber cloths are further complicated by studies reporting variations in performance among different types of microfiber cloths. ${ }^{[49,53]} \mathrm{A}$ limitation of using microfiber or cotton cloths is the potential reduction of disinfectant and detergent efficacy. Chemical concentrations may decrease when applied with a reusable cloth causing the disinfectant or detergent to fall below the manufacturer recommended concentration for use. ${ }^{[52,54]}$ When using reusable cloths, the chemical concentrations of disinfectants and detergents must be checked often to ensure proper concentrations are maintained. ${ }^{[52]}$ Using an immersion technique may increase compliance on maintaining recommended chemical concentrations.

A major aspect of the cleaning protocol is the type of cleaning employed. Types of cleaning include daily (routine) or terminal (discharge). Enforcement of routine cleaning is required to sustain the improvement. ${ }^{[31]}$ Furthermore, incorporating routine environmental cleaning multiple times a day may help achieve reduced microbial contamination when compared to cleaning once daily. ${ }^{[55]}$ Enhanced terminal cleaning was also found to decrease risk of acquisition of pathogens. ${ }^{[56]}$ Microbial diversity may be significantly lowered with a coupled cleaning approach including daily (routine) and terminal (discharge) cleaning. ${ }^{29,30]}$ However, different hospitals have shown to have varied applications of daily, routine, terminal and discharge cleaning. For example, Amin, Folkert ${ }^{[29]}$ applied terminal cleaning at the end of each day and routine cleaning between patients during the day in intravitreal injection rooms while Chen, $\mathrm{Tu}^{[30]}$ applied terminal cleaning after a patient is discharged with daily cleaning while a patient remains in one hospital room. The differ- 
ences in setting among these studies show that frequency of cleaning will vary depending on the number of patients, length of stay, and type of illness or treatment. Despite these differences, it is possible to improve cleanliness and reduce HAIs by coupling intermittent frequent cleaning (daily or routine) with final cleaning (terminal or discharge).

Adequate education and training of EVS staff is important to ensure correct application and consistency in cleaning protocols. A component of environmental cleaning controlled by EVS staff is the amount of time that HTOs are exposed to detergent or disinfectant chemicals which may also affect the efficacy of a cleaning procedure. Proper cleaning time is determined by use instructions of the selected disinfectant or detergent, often recommending a 10-minute wet exposure time. ${ }^{[6]}$ However, studies have shown to be effective with chemical contact times of at least one minute. ${ }^{[6]}$ While there are multiple factors impacting cleaning times such as surface dimensions, type of cleaning (daily or terminal), and type of disinfectant or detergent used, it is most important to ensure appropriate and uniform cleaning compliance among EVS staff. In this review, cleaning times for commonly contaminated HTOs varied. Boyce, Havill ${ }^{[27]}$ reported variations in cleaning time among individual EVS staff, while Scott, Kane ${ }^{[28]}$ found no variations among EVS staff cleaning times. Studies indicate that improving cleaning compliance and environmental surface cleanliness may be achieved with education and training utilizing auditing systems. ${ }^{[33,39,57-76]}$ However, a recent study by Mitchell, White ${ }^{[77]}$ reported that EVS staff have a high level of understanding in knowledge and of the importance of their role, but that there is a perceived lack of organizational support, investment in cleaning resources and feedback. When aiming to improve hospital cleanliness, the morale and attitudes of EVS staff must be considered as a determinant of the cleaning protocol.

Multiple studies in this review show that utilizing a cleaning monitoring system may be a quick and easy way to improve thoroughness of cleaning and compliance among EVS staff. $^{[31-35,37,38,40,78,79]}$ Conversely, Knelson, Control ${ }^{[80]}$ found that EVS self-monitoring of cleaning environmental surfaces may not be accurate and that further validation of surface cleanliness may be necessary. When choosing cleanliness monitoring systems, hospitals have many options which all report results differently. Options for monitoring cleaning include visual assessment, surface swabbing for aerobic colony counts, ATP bioluminescence, and UV fluorescence markers The two most common methods were ATP and UV. ${ }^{[64]}$ While both methods have been found to be effective in monitoring cleanliness, there are limitations to both. For example, UV fluorescent markers are reported qualitatively on a pass/fail basis and ATP bioluminescence is a quantitative method reporting relative light units (RLUs). For both methods, there must be clear definitions of clean. For UV fluorescent markers, it must be determined whether some marker removal or entire marker removal is the benchmark for clean. ${ }^{[81]}$ For ATP technology, there is no standard for determining the pass/fail for RLUs. ${ }^{[82]}$ Establishing a meaningful RLU reporting value for clean/not clean is an important factor to provide consistent results.

No touch decontamination methods are another technological option for cleaning protocols but were not examined in this review. No touch decontamination methods include aerosolized hydrogen peroxide, hydrogen peroxide vapor systems, ultraviolet light, and others. ${ }^{[83]}$ No touch decontamination methods may be effective ways to reduce nosocomial pathogens on environmental surfaces, and should be further explored when establishing cleaning protocols. ${ }^{[84,85]}$

Self-disinfecting surfaces may be a potential method for reducing environmental contamination in hospital settings. These surfaces are often created by impregnating or coating surfaces with metals, germicides, and other compounds which have antimicrobial abilities. ${ }^{[83,86-88]}$ Copper is a specific heavy metal which has demonstrated an ability to reduce microbes on environmental surfaces. ${ }^{\left[{ }^{88-91]}\right.}$ Silver and other metal-alloys have also been used in impregnated privacy curtains and other fabrics to decrease pathogen transmission. ${ }^{[88,92,93]}$ While self-disinfecting surfaces were not addressed in this review, further research is needed to investigate their true efficacy and practical application in the hospital setting.

Limitations of this study are associated with the diversity across variables such as the variety of healthcare environments. Studies were carried out in different environments such as intensive care units, medical surgical units, rehabilitation units, out-patient units, and laboratories. The specific type of healthcare setting determined the type of cleaning protocols, making comparisons of the included studies difficult. Second, the studies used a variety of chemical agents. While this study focused on the effectiveness of various cleaning protocols, the evidence indicated that cleaning effectiveness varied due to the type of chemicals, such as sodium hypochlorite (bleach), alcohol, hydrogen peroxide, or quaternary ammonium compounds. Test pathogens varied across the studies, increasing difficulty in comparative analysis. Some studies evaluated cleaning effectiveness based on reduction of overall surface bioburden, while others focused on specific pathogens like $C$. diff, MRSA, or VRE. A variety of environmental surfaces or HTOs to test aspects of the cleaning protocols were used across the studies. The inconsistency of the environmental surface selected increased 
difficulty in comparative analysis.

The results of this review and the current literature indicate that implementing environmental cleaning protocols in the hospital setting is complex and requires consideration of multiple factors. It is recommended that mechanical wiping action be used to clean surfaces with further investigation of the chosen materials intended for use. Current research is limited on the use of disposable pre-soaked wipes, cotton cloths, and microfiber cloths. Reprocessing of reusable wipes must be tested to ensure that reusable wipes are in fact free of microbes and potential nosocomial pathogens to mitigate recontamination or cross contamination. Based on the literature, it is recommended that disposable and reusable wipes have set locations in the patient environment, set standards for length of time used and number of applications to prevent cross contamination from surface to surface when cleaning. It is recommended that EVS staff receive adequate, consistent, education and evaluation to ensure compliance to the determined protocols. EVS staff must be adequately assessed to ensure correct chemical contact times, wipe use, and that HTOs are disinfected according to the protocols. Lastly, in education, training and evaluation of EVS staff, the use of a monitoring system is recommended. Feedback is an important component of cleaning and disinfecting protocols to inform EVS staff of the effectiveness of their performance to make necessary adjustments in the protocol or compliance to mitigate contamination of environmental surfaces.

\section{Conclusions}

In conclusion, cleaning protocols of hospital settings are complex and require that all factors be taken into consid- eration to prevent the spread of nosocomial pathogens and the acquisition of HAIs. Components of cleaning and disinfecting protocols that were found to be instrumental in adequately cleaning and disinfecting environmental surfaces include: 1) mechanical cleaning action: 2) chemical application materials; 3 ) types of cleaning; 4) chemical contact times; 5) education and training of EVS staff; 6) monitoring and feedback; 7) no-contact cleaning methods; and 8) self-disinfecting surfaces. No-contact cleaning methods and self-disinfecting surfaces were not thoroughly evaluated for this review, however, there is a need for further investigation of various methods, technologies, and comparative efficacies.

Across the studies, cleaning agents, methods, organisms, and surface materials varied. Cleaning agent exposure times and application methods varied. A comparative analysis is limited by the lack of structured methods. Proposing a framework with a consensus for standardized quantitative assessment would begin to fill the gaps in the evidence and provide a structure for a stronger comparative analysis methodology. This review addressed the complexities involved in developing or selecting protocols for cleaning and disinfecting environmental surfaces and preventing HAI acquisition.

\section{ACKNOWLEDgements}

The authors disclosed receipt of the following financial support for the research: This work was supported by the Healthcare Surfaces Institute.

\section{CONFlicts OF InTEREST Disclosure}

The authors declare they have no conflicts of interest.

\section{REFERENCES}

[1] Han JH, Sullivan N, Leas BF, et al. Cleaning hospital room surfaces to prevent health care-associated infections: a technical brief. Annals of Internal Medicine. 2015; 163(8): 598-607. PMid: 26258903. https://doi.org/10.7326/M15-1192

[2] Klevens RM, Edwards JR, Richards Jr CL, et al. Estimating health care-associated infections and deaths in US hospitals, 2002. Public Health Reports. 2007; 122(2): 160-6. PMid: 17357358. https : //doi.org/10.1177/003335490712200205

[3] Magill SS, Edwards JR, Bamberg W, et al. Multistate pointprevalence survey of health care-associated infections. New England Journal of Medicine. 2014 Mar; 370(13): 1198-208. PMid: 24670166. https://doi.org/10.1056/NEJMoa1306801

[4] Babbush CA, Zwemer TJ, Fehrenbach MJ, et al. Mosby's dental dictionary. Mosby Inc; 2007.

[5] Spaulding E. Chemical disinfection and antisepsis in the hospital. J Hosp Research. 1957; 9: 5-31.
[6] Rutala WA, Weber DJ, HICPAC. Guideline for Disinfection and Sterilization in Healthcare Facilities, 2008. Atlanta, GA. Updated February 15, 2017; 5341.

[7] Siegel JD, Rhinehart E, Jackson M, et al. 2007 guideline for isolation precautions: preventing transmission of infectious agents in health care settings. American Journal of Infection Control. 2007 Dec; 35(10): S65-S164. PMid: 18068815. https://doi.org/10 $.1016 / j$.ajic. 2007.10.007

[8] Sehulster L, Chinn RYW, Arduino MJ, et al. Guidelines for environmental infection control in health-care facilities. United States: American Society for Healthcare Engineering/American Hospital Association. 2003; 52(RR-10): 79

[9] Dancer SJ. Hospital cleaning in the 21st century. Eur J Clin Microbiol Infect Dis. 2011 Dec; 30(12): 1473-81. PMid: 21499954 https://doi.org/10.1007/s10096-011-1250-x

[10] Diab-Elschahawi M, Assadian O, Blacky A, et al. Evaluation of the decontamination efficacy of new and reprocessed microfiber cleaning cloth compared with other commonly used cleaning cloths in 
the hospital. Am J Infect Control. 2010 May; 38(4): 289-92. PMid: 20123151. https://doi.org/10.1016/j.ajic. 2009.09.006

[11] Williams GJ, Denyer SP, Hosein IK, et al. The development of a new three-step protocol to determine the efficacy of disinfectant wipes on surfaces contaminated with Staphylococcus aureus. J Hosp Infect. 2007 Dec; 67(4): 329-35. PMid: 17945392. https: //doi.org/10.1016/j.jhin.2007.08.012

[12] Higgins J, Green S. Cochrane Handbook for Systematic Reviews of Interventions Version 5.1.6. 2011 [updated September 2018]. Available from: http://handbook. cochrane.org

[13] Detke LA, Harris DD, Particini CA. Hospital facility design's influence on health care workers. The Internet Journal of Healthcare Administration. 2013 Aug; 8(2).

[14] Cohen J. A coefficient of agreement for nominal scales. Educational and Psychological Measurement. 1968; 20: 37-46. https: //doi.org/10.1177/001316446002000104

[15] Concato J, Shah N, Horwitz R. Randomized, controlled trials, observational studies, and the hierarchy of research designs. The New England Journal of Medicine. 2000; 342(25): 1887-92. PMid: 10861325. https://doi.org/10.1056/NEJM200006223422507

[16] Evans D. Hierarchy of evidence: a framework for ranking evidence evaluating healthcare interventions. Journal of Clinical Nursing. 2003; 12(77-84). PMid: 12519253. https://doi.org/10.1046/ j.1365-2702.2003.00662.x

[17] Torraco RJ. Writing Integrative Literature Reviews: Guidelines and Examples. Human Resource Development Review. 2005; 4(3): 35667. https://doi.org/10.1177/1534484305278283

[18] Whittemore R, Knafl K. The integrative review: updated methodology. Journal of Advanced Nursing. 2005; 52(5): 546-53. PMid: 16268861. https://doi.org/10.1111/j.1365-2648.2005.0 3621. $\mathrm{x}$

[19] Cooper HM. Scientific Guidelines for Conducting Integrative Research Reviews. Review of Educational Research. 1982; 52: 291-302. https://doi.org/10.3102/00346543052002291

[20] Cooper HM. Synthesizing Research: A Guide for Literature Reviews. Newbury Park, CA: Sage Publications; 2001.

[21] White LF, Dancer SJ, Robertson C. A microbiological evaluation of hospital cleaning methods. Int J Environ Health Res. 2007 Aug; 17(4): 285-95. PMid: 17613092. https://doi .org/10.1080/09 603120701372433

[22] Moher D, Liberati A, Tetzlaff J, et al. Preferred reporting items for systematic reviews and meta-analyses: the PRISMA statement. J Clin Epidemiol. 2009 Oct; 62(10): 1006-12. PMid: 19631508. https://doi.org/10.1016/j.jclinepi.2009.06.005

[23] Wong SS, Huang CH, Yang CC, et al. Reducing health careassociated infections by implementing separated environmental cleaning management measures by using disposable wipes of four colors. Antimicrob Resist Infect Control. 2018; 7(34). PMid: 29541446. https://doi.org/10.1186/s13756-018-0320-6

[24] Hopman J, Nillesen M, de Both E, et al. Mechanical vs. manual cleaning of hospital beds: a prospective intervention study. J Hosp Infect. 2015 Jun; 90(2): 142-6. PMid: 25804978. https: //doi.org/10.1016/j.jhin.2014.12.023

[25] Li QF, Xu H, Ni XP, et al. Impact of relocation and environmental cleaning on reducing the incidence of healthcare-associated infection in NICU. World J Pediatr. 2017 Jun; 13(3): 217-21. PMid: 28101771. https://doi.org/10.1007/s12519-017-0001-1

[26] Mehmi M, Marshall LJ, Lambert PA, et al. Evaluation of disinfecting procedures for aseptic transfer in hospital pharmacy departments PDA J Pharm Sci Technol. 2009 Mar-Apr; 63(2): 123-38.

[27] Boyce JM, Havill NL, Lipka A, et al. Variations in hospital daily cleaning practices. Infection Control And Hospital Epidemiology.
2010 Jan; 31(1): 99-101. PMid: 19951203. https ://doi.org/10 $.1086 / 649225$

[28] Scott D, Kane H, Rankin A. Time to clean: A systematic review and observational study on the time required to clean items of reusable communal patient care equipment. J Infect Prev. 2017 Nov; 18(6): 289-94. PMid: 29344098. https://doi.org/10.1177/175717 7417714046

[29] Amin SR, Folkert CM, Erie JC. Assessing the effectiveness of surface cleaning methods in intravitreal injection procedure rooms. Ophthalmology. 2014 Jan; 121(1): 276-82. PMid: 24112945. https: //doi.org/10.1016/j.ophtha.2013.08.006

[30] Chen CH, Tu CC, Kuo HY, et al. Dynamic change of surface microbiota with different environmental cleaning methods between two wards in a hospital. Appl Microbiol Biotechnol. 2017 Jan; 101(2): 771-81. PMid: 27771740. https://doi.org/10.1007/s00253 -016-7846-4

[31] Carling P, Parry M, Rupp M, et al. Improving cleaning of the environment surrounding patients in 36 acute care hospitals. Infection Control \& Hospital Epidemiology. 2008 Nov; 29(11): 1035-41. PMid: 18851687. https://doi.org/10.1086/591940

[32] Carling PC, Briggs J, Hylander D, et al. An evaluation of patient area cleaning in 3 hospitals using a novel targeting methodology. Am J Infect Control. 2006 Oct; 34(8): 513-9. PMid: 17015157. https://doi.org/10.1016/j.ajic. 2005.09.001

[33] Carling PC, Briggs JL, Perkins J, et al. Improved cleaning of patient rooms using a new targeting method. Clin Infect Dis. 2006 Feb 1; 42(3): 385-8. PMid: 16392086. https://doi.org/10.1086/49 9361

[34] Carling PC, Parry MF, Bruno-Murtha LA, et al. Improving environmental hygiene in 27 intensive care units to decrease multidrugresistant bacterial transmission. Crit Care Med. 2010 Apr; 38(4): 1054-9. PMid: 20081531. https://doi.org/10.1097/CCM.0b 013e3181cdf705

[35] Carling PC, Von Beheren S, Kim P, et al. Intensive care unit environmental cleaning: an evaluation in sixteen hospitals using a novel assessment tool. J Hosp Infect. 2008 Jan; 68(1): 39-44. PMid: 18069083. https://doi.org/10.1016/j.jhin.2007.09.015

[36] Munoz-Price LS, Birnbach DJ, Lubarsky DA, et al. Decreasing operating room environmental pathogen contamination through improved cleaning practice. Infect Control Hosp Epidemiol. 2012 Sep; 33(9): 897-904. PMid: 22869263. https://doi.org/10.1086/667381

[37] Ragan K, Khan A, Zeynalova N, et al. Use of audit and feedback with fluorescent targeting to achieve rapid improvements in room cleaning in the intensive care unit and ward settings. Am J Infect Control. 2012 Apr; 40(3): 284-6. PMid: 21820762. https: //doi.org/10.1016/j.ajic.2011.04.003

[38] Eckstein BC, Adams DA, Eckstein EC, et al. Reduction of Clostridium Difficile and vancomycin-resistant Enterococcus contamination of environmental surfaces after an intervention to improve cleaning methods. BMC Infect Dis. 2007 Jun 21; 7(61). PMid: 17584935. https://doi.org/10.1186/1471-2334-7-61

[39] Goodman ER, Platt R, Bass R, et al. Impact of an environmental cleaning intervention on the presence of methicillin-resistant Staphylococcus aureus and vancomycin-resistant enterococci on surfaces in intensive care unit rooms. Infect Control Hosp Epidemiol. 2008 Jul; 29(7): 593-9. PMid: 18624666. https://doi.org/10.1086/588566

[40] Sitzlar B, Deshpande A, Fertelli D, et al. An environmental disinfection odyssey: evaluation of sequential interventions to improve disinfection of Clostridium difficile isolation rooms. Infect Control Hosp Epidemiol. 2013 May; 34(5): 459-65. PMid: 23571361. https://doi.org/10.1086/670217 
[41] Assanta MA, Massicotte R, Pichette G, et al. Importance of mechanical action in a terminal disinfection process for decontamination of Clostridium difficile spores on hospital inert contact surfaces. Int J Infect Control. 2014; 11(i3).

[42] Cadnum JL, Hurless KN, Kundrapu S, et al. Transfer of Clostridium difficile spores by nonsporicidal wipes and improperly used hypochlorite wipes practice + product $=$ perfection. Infection Control \& Hospital Epidemiology. 2013; 34(4): 441-2. PMid: 23466922. https://doi.org/10.1086/669871

[43] Sattar SA, Bradley C, Kibbee R, et al. Disinfectant wipes are appropriate to control microbial bioburden from surfaces: use of a new ASTM standard test protocol to demonstrate efficacy. J Hosp Infect. 2015 Dec; 91(4): 319-25. PMid: 26518272. https : //doi.org/10.1016/j.jhin.2015.08.026

[44] Ramm L, Siani H, Wesgate R, et al. Pathogen transfer and high variability in pathogen removal by detergent wipes. Am J Infect Control. 2015 Jul 1; 43(7): 724-8. PMid: 25997876. https: //doi.org/10.1016/j.ajic.2015.03.024

[45] Kampf G, Degenhardt S, Lackner S, et al. Poorly processed reusable surface disinfection tissue dispensers may be a source of infection. BMC infectious diseases. 2014; 14(1): 37. PMid: 24447780. https://doi.org/10.1186/1471-2334-14-37

[46] Ali S, Moore G, Wilson AP. Effect of surface coating and finish upon the cleanability of bed rails and the spread of Staphylococcus aureus. J Hosp Infect. 2012 Mar; 80(3): 192-8. PMid: 22264495. https://doi.org/10.1016/j.jhin.2011.12.005

[47] Rutala WA, Gergen MF, Weber DJ. Microbiologic evaluation of microfiber mops for surface disinfection. Am J Infect Control. 2007 Nov; 35(9): 569-73. PMid: 17980233. https://doi.org/10.101 $6 / j$.ajic.2007.02.009

[48] Trajtman AN, Manickam K, Alfa MJ. Microfiber cloths reduce the transfer of Clostridium difficile spores to environmental surfaces compared with cotton cloths. Am J Infect Control. 2015 Jul 1; 43(7): 686-9. PMid: 25907782. https://doi.org/10.1016/j.ajic.2 015.03 .002

[49] Moore G, Griffith C. A laboratory evaluation of the decontamination properties of microfibre cloths. Journal of Hospital Infection. 2006; 64(4): 379-85. PMid: 17055112. https://doi.org/10.1016/j. jhin.2006.08.006

[50] Bergen LK, Meyer M, Hog M, et al. Spread of bacteria on surfaces when cleaning with microfibre cloths. J Hosp Infect. 2009 Feb; 71(2): 132-7. PMid: 19108933. https://doi .org/10.1016/j.jhin.2 008.10 .025

[51] Sifuentes LY, Gerba CP, Weart I, et al.. Microbial contamination of hospital reusable cleaning towels. Am J Infect Control. 2013 Oct; 41(10): 912-5. PMid: 23523522. https://doi.org/10.1016/j. ajic.2013.01.015

[52] Boyce JM, Sullivan L, Booker A, et al. Quaternary Ammonium Disinfectant Issues Encountered in an Environmental Services Department. Infect Control Hosp Epidemiol. 2016 Mar; 37(3): 340-2. PMid: 26821275. https://doi.org/10.1017/ice.2015.299

[53] Smith DL, Gillanders S, Holah JT, et al. Assessing the efficacy of different microfibre cloths at removing surface micro-organisms associated with healthcare-associated infections. J Hosp Infect. 2011 Jul; 78(3): 182-6. PMid: 21501897. https ://doi .org/10.1016/ j.jhin.2011.02.015

[54] Engelbrecht K, Ambrose D, Sifuentes L, et al. Decreased activity of commercially available disinfectants containing quaternary ammonium compounds when exposed to cotton towels. American Journal of Infection Control. 2013; 41(10): 908-11. PMid: 23623007. https://doi.org/10.1016/j.ajic.2013.01.017
[55] Dharan S, Mourouga P, Copin P, et al. Routine disinfection of patients' environmental surfaces. Myth or reality? J Hosp Infect. 1999 Jun; 42(2): 113-7. PMid: 10389060. https://doi.org/10.105 3/jhin.1999.0567

[56] Anderson DJ, Chen LF, Weber DJ, et al. Enhanced terminal room disinfection and acquisition and infection caused by multidrug-resistant organisms and Clostridium difficile (the Benefits of Enhanced Terminal Room Disinfection study): a cluster-randomised, multicentre, crossover study. Lancet. 2017 Feb 25; 389(10071): 805-14. https://doi.org/10.1016/S0140-6736(16)31588-4

[57] Anderson R, Young V, Stewart M, et al. Cleanliness audit of clinical surfaces and equipment: who cleans what? Journal of Hospital Infection. 2011; 78(3): 178-81. PMid: 21497943. https: //doi.org/10.1016/j.jhin.2011.01.030

[58] Bovee M, Carranza E, Rupp A, et al. Post-discharge Cleaning Evaluation of High-touch Environmental Surfaces: A Stepping Stone in Advancing Cleaning Practices. American Journal of Infection Control. 2014; 42(6): S44. https ://doi.org/10.1016/j.ajic. 201 4.03 .116

[59] Boyce JM, Havill NL, Dumigan DG, et al. Monitoring the effectiveness of hospital cleaning practices by use of an adenosine triphosphate bioluminescence assay. Infect Control Hosp Epidemiol. 2009 Jul; 30(7): 678-84. PMid: 19489715. https://doi .org/10.108 $6 / 598243$

[60] Branch-Elliman W, Robillard E, McCarthy G, Jr., et al. Direct feedback with the ATP luminometer as a process improvement tool for terminal cleaning of patient rooms. Am J Infect Control. $2014 \mathrm{Feb}$; 42(2): 195-7. PMid: 24485376. https://doi.org/10.1016/j. ajic.2013.08.012

[61] Carling P. Methods for assessing the adequacy of practice and improving room disinfection. Am J Infect Control. 2013 May; 41 (5 Suppl): S20-5. PMid: 23622743. https://doi.org/10.1016/j. ajic. 2013.01.003

[62] Dumigan DG, Boyce JM, Havill NL, et al. Who is really caring for your environment of care? Developing standardized cleaning procedures and effective monitoring techniques. Am J Infect Control. 2010 Jun; 38(5): 387-92. PMid: 20435376. https ://doi .org/10 $.1016 /$ j.ajic. 2009. 07.005

[63] Gordon L, Bruce N, Suh KN, et al. Evaluating and operationalizing an environmental auditing program: a pilot study. Am J Infect Control. 2014 Jul; 42(7): 702-7. PMid: 24969123. https : //doi.org/10.1016/j.ajic.2014.04.007

[64] Guh A, Carling P. Options for evaluating environmental cleaning. Healthcare-associated infections: options for evaluating environmental cleaning. 2010 Dec; Available from: https://www.cdc.gov/hai/toolkits/evaluating-envir onmental-cleaning.html

[65] Hopman J, Donskey CJ, Boszczowski I, et al. Multisite evaluation of environmental cleanliness of high-touch surfaces in intensive care unit patient rooms. Am J Infect Control. 2018 May 23. PMid: 29803595. https://doi.org/10.1016/j.ajic.2018.03.031

[66] Huang YS, Chen YC, Chen ML, et al. Comparing visual inspection, aerobic colony counts, and adenosine triphosphate bioluminescence assay for evaluating surface cleanliness at a medical center. Am J Infect Control. 2015 Aug; 43(8): 882-6. PMid: 25952617. https://doi.org/10.1016/j.ajic.2015.03.027

[67] Luick L, Thompson PA, Loock MH, et al. Diagnostic assessment of different environmental cleaning monitoring methods. Am J Infect Control. 2013 Aug; 41(8): 751-2. PMid: 23380380. https : //doi.org/10.1016/j.ajic.2012.09.019

[68] Malik RE, Cooper RA, Griffith CJ. Use of audit tools to evaluate the efficacy of cleaning systems in hospitals. Am J Infect Control. 2003 
May; 31(3): 181-7. PMid: 12734526. https://doi.org/10.106 $7 / \mathrm{mic} .2003 .34$

[69] Ramphal L, Suzuki S, McCracken IM, et al. Improving hospital staff compliance with environmental cleaning behavior. Proc (Bayl Univ Med Cent). 2014 Apr; 27(2): 88-91. PMid: 24688183. https://doi.org/10.1080/08998280.2014.11929065

[70] Rupp ME, Fitzgerald T, Sholtz L, et al. Maintain the gain: program to sustain performance improvement in environmental cleaning. Infection Control \& Hospital Epidemiology. 2014; 35(7): 866-8. PMid: 24915215. https://doi.org/10.1086/676873

[71] Sherlock O, O'Connell N, Creamer E, et al. Is it really clean? An evaluation of the efficacy of four methods for determining hospital cleanliness. J Hosp Infect. 2009 Jun; 72(2): 140-6. PMid: 19321226. https://doi.org/10.1016/j.jhin.2009.02.013

[72] Siani H, Maillard JY. Best practice in healthcare environment decontamination. Eur J Clin Microbiol Infect Dis. 2015 Jan; 34(1): 1-11. PMid: 25060802. https://doi.org/10.1007/s10096-0 14-2205-9

[73] Smith PW, Beam E, Sayles H, et al. Impact of adenosine triphosphate detection and feedback on hospital room cleaning. Infect Control Hosp Epidemiol. 2014 May; 35(5): 564-9. PMid: 24709726. https://doi.org/10.1086/675839

[74] Trajtman AN, Manickam K, Macrae M, et al. Continuing performance feedback and use of the ultraviolet visible marker to assess cleaning compliance in the healthcare environment. J Hosp Infect. 2013 Jun; 84(2): 166-72. PMid: 23631799. https : //doi .org/10 $.1016 / j \cdot j h i n .2013 .03 .004$

[75] Xu H, Jin H, Zhao L, et al. A randomized, double-blind comparison of the effectiveness of environmental cleaning between infection control professionals and environmental service workers. Am J Infect Control. 2015 Mar 1; 43(3): 292-4. PMid: 25556049. https://doi.org/10.1016/j.ajic.2014.11.009

[76] Zelikoff AJ, Dellit TH, Lynch J, et al. Cleaning practices in the hospital setting: Are high-touch surfaces in isolation and standard precaution patient rooms cleaned to the same standard? Am J Infect Control. 2016 Nov 1; 44(11): 1399-400. PMid: 27317406. https://doi.org/10.1016/j.ajic.2016.04.220

[77] Mitchell BG, White N, Farrington A, et al. Changes in knowledge and attitudes of hospital environmental services staff: The Researching Effective Approaches to Cleaning in Hospitals (REACH) study. Am J Infect Control. 2018 Sep; 46(9): 980-985. PMid: 29550084. https://doi.org/10.1016/j.ajic.2018.02.003

[78] Carling PC. Optimizing Health Care Environmental Hygiene. Infect Dis Clin North Am. 2016 Sep; 30(3): 639-60. PMid: 27515141. https://doi.org/10.1016/j.idc.2016.04.010

[79] Gillespie E, Williams N, Sloane T, et al. Using microfiber and steam technology to improve cleaning outcomes in an intensive care unit. Am J Infect Control. 2015 Feb; 43(2): 177-9. PMid: 25637118. https://doi.org/10.1016/j.ajic.2014.11.006

[80] Knelson LP, Ramadanovic GK, Chen LF, et al. Self-monitoring by environmental services may not accurately measure thoroughness of hospital room cleaning. Inf Control Hosp Epidemiol. 2017 Oct; 38(11): 1371-1373. PMid: 29025436. https://doi.org/10.101 $7 /$ ice. 2017.205
[81] Fattorini M, Ceriale E, Nante N, et al. Use of a fluorescent marker for assessing hospital bathroom cleanliness. Am J Infect Control. 2016 Sep 1; 44(9): 1066-8. PMid: 27179392. https ://doi .org/10.1 016/j.ajic.2016.03.030

[82] Nante N, Ceriale E, Messina G, et al. Effectiveness of ATP bioluminescence to assess hospital cleaning: a review. J Prev Med Hyg. 2017 Jun; 58(2): E177-E83.

[83] Boyce JM. Modern technologies for improving cleaning and disinfection of environmental surfaces in hospitals. Antimicrob Resist Infect Control. 2016 Apr 11; 5(10). PMid: 27069623. https : //doi.org/10.1186/s13756-016-0111-x

[84] Otter JA, Yezli S, Perl TM, et al. The role of 'no-touch' automated room disinfection systems in infection prevention and control. J Hosp Infect. 2013 Jan; 83(1): 1-13. PMid: 23195691. https://doi.org/10.1016/j.jhin.2012.10.002

[85] Weber DJ, Kanamori H, Rutala WA. 'No touch' technologies for environmental decontamination: focus on ultraviolet devices and hydrogen peroxide systems. Curr Opin Infect Dis. 2016 Aug; 29(4): 424-31. PMid: 27257798. https://doi.org/10.1097/QC0.00 00000000000284

[86] Weber DJ, Rutala WA. Self-disinfecting surfaces: review of current methodologies and future prospects. Am J Infect Control. 2013 May; 41(5 Suppl): S31-5. PMid: 23622745. https://doi .org/10.101 6/j.ajic.2012.12.005

[87] Baxa D, Shetron-Rama L, Golembieski M, et al. In vitro evaluation of a novel process for reducing bacterial contamination of environmental surfaces. American Journal of Infection Control. 2011; 39(6):4837. PMid: 21616563. https://doi.org/10.1016/j.ajic. 2010. 10.015

[88] Humphreys H. Self-disinfecting and microbiocide-impregnated surfaces and fabrics: what potential in interrupting the spread of healthcare-associated infection? Clinical Infectious Diseases. 2013; 58(6): 848-53. PMid: 24265359. https ://doi .org/10.1093/ci d/cit765

[89] Salgado CD, Sepkowitz KA, John JF, et al. Copper surfaces reduce the rate of healthcare-acquired infections in the intensive care unit Infect Control Hosp Epidemiol. 2013 May; 34(5): 479-86. PMid: 23571364. https://doi.org/10.1086/670207

[90] Schmidt MG, Attaway HH, Sharpe PA, et al. Sustained reduction of microbial burden on common hospital surfaces through introduction of copper. J Clin Microbiol. 2012 Jul; 50(7): 2217-23. PMid: 22553242. https://doi.org/10.1128/JCM.01032-12

[91] Schmidt MG, von Dessauer B, Benavente C, et al. Copper surfaces are associated with significantly lower concentrations of bacteria on selected surfaces within a pediatric intensive care unit. Am J Infect Control. 2016 Feb; 44(2): 203-9. PMid: 26553403. https://doi.org/10.1016/j.ajic.2015.09.008

[92] Kotsanas D, Wijesooriya W, Sloane T, et al. The silver lining of disposable sporicidal privacy curtains in an intensive care unit. American Journal of Infection Control. 2014; 42(4): 366-70. PMid: 24679561. https://doi.org/10.1016/j.ajic.2013.11.013

[93] Schweizer M, Graham M, Ohl M, et al. Novel hospital curtains with antimicrobial properties: a randomized, controlled trial. Infection Control \& Hospital Epidemiology. 2012; 33(11): 1081-5. PMid: 23041804. https://doi.org/10.1086/668022 